[This is the pre-publication version of Henry, A. (2014). Swedish students' beliefs about learning English in and outside of school. In D. Lasagabaster, A. Doiz and J-M Sierra (eds). Motivation and Foreign Language Learning: From Theory to Practice [Language Learning \& Language Teaching, 40] (pp. 93-116). Amsterdam: John Benjamins]

\title{
Introduction
}

In Sweden students' encounters with English in and out of school are very different. Spending around 20 hours per week in English-mediated environments outside of school, they are often engaged in richly meaningful activities. Consequently, many young people believe they learn as much of their English as a result of participation in English-mediated leisure time activities as they do from textbook-dominated classroom instruction. Drawing on emerging discussions on the ways in which learners' beliefs about the primacy of learning English in natural environments can have negative effects on learning behaviours in formal settings (e.g. Mercer \& Ryan, 2010), and how learners' beliefs about the causes of success in language learning can impact on motivation (e.g. Hsieh, 2012), this chapter examines the ways in which such beliefs may impact on Swedish students' responses to classroom learning. Further, in view of the fact that beliefs about the context in which English is mostly acquired differ substantially between girls and boys, the chapter examines the ways in which gender differences in the nature of self-regulation can impact on students’ beliefs.

\section{The setting}

As a backdrop to the discussions that follow, three aspects of the social/societal context in which young people in Sweden grow up are worth highlighting. First, Sweden is a small linguistic community, second, levels of English language proficiency are generally high, and third, Sweden is currently the world leader in technological development and Internet access/use.

\section{A small linguistic community}

With little more than 10 million speakers of Swedish worldwide, nearly all of the foreign cultural media imported into Sweden (primarily from the US and the UK) is broadcast and published in English. With the exception of offerings for the very youngest children, television programs are not dubbed into Swedish, instead having Swedish subtitles. Similarly, although there is an abundance of Swedish-mediated Internet sites in all imaginable fields, 
people in Sweden are generally accustomed to searching for information and carrying out business transactions and social interaction via English-mediated sites. Furthermore, since English functions as the default language in digital gaming (Waters, 2007) - which, as elsewhere, is an extremely popular activity among young people in Sweden (particularly boys) - both casual and serious gaming often takes place in English.

\section{High levels of English language proficiency}

People living in Sweden are generally regarded as being good at English, and in two recent international surveys Sweden has emerged as the country with the highest levels of English language proficiency. In the European Commission’s Survey on Language Competences, SurveyLang, (European Commission, 2012), more 14-15 year-old students in Sweden than in any of the other 15 countries surveyed were assessed to be in the Common European Framework B2 'upper intermediate user' category for both reading and listening. ${ }^{i}$ Similarly, in a survey assessing levels of adults' skills in English commissioned by EF, the language education provider, the Swedish respondents were ranked first among the 54 participating countries. ${ }^{\text {ii }}$ Not only do the vast majority of young people in Sweden gain passing grades or higher in English at secondary and upper secondary levels, but CLIL (Content and Language Integrated Learning) programs at the upper secondary level are not uncommon (Sylvén, 2013) and an increasing number of university courses and programs are now being provided in English (see e.g. Airey, 2009).

\section{Technologically advanced with universal Internet use}

In Sweden there is almost universal access to high-speed broadband Internet and in the World Economic Forum’s ‘Networked Readiness Index’ (World Economic Forum, Global Information Technology Report, 2012) Sweden was ranked first of 142 countries. 'Networked readiness' gauges everyday technological affordances including a society’s ICT (Information and Communication Technology) uptake, its preparation to make good use of an affordable ICT infrastructure, the efforts of the main social agents to increase their capacity to use ICT, ICT use in day-to-day activities, and the social impacts accruing from ICT. Ownership of a computer is common among young people in Sweden. According to the Swedish Media Council (2013), in 2012/2013 81\% of 13-16 year-olds owned their own computer (with the remaining $19 \%$ having access to one in the family), and $99 \%$ of the same age group owned their own mobile phone. As the Media Council has shown, the use of the Internet is almost universal among young people, with 93\% of 13-16 year-olds reporting using the Internet 
every day, with the remaining 7\% reporting being online frequently during the week. Moreover, using the Internet - for surfing, social networking and playing digital games - was by far the most commonly reported free-time activity for all age groups (Swedish Media Council, 2013).

\section{Out-of-school encounters with English}

\section{Extent, scope and impact on language acquisition}

Many of the online activities, digital games, music, and TV programs popular among young people in Sweden are mediated in English (Swedish Media Council, 2013). While in some cases Swedish language alternatives do not exist, in other cases they are not as attractive. For example, the most popular TV series watched by Swedish youngsters in the 13-16 age bracket in 2012/2013 were Family Guy (24\% watching regularly) The Simpsons (22\%) and How I met your Mother (15\%). All of these programs are broadcast in English with Swedish subtitles. For digital gaming, the four most popular games played by young people aged 13-16 in the same period were FIFA (26\%), Call of Duty (COD) (23\%), Minecraft (20\%) and League of Legends (LOL) (16\%), with other popular games including Battlefield and World of Warcraft (WOW), each played by 9\% of boys (Swedish Media Council, 2013). With the exception of Minecraft and FIFA, which can be played using Swedish language settings, ${ }^{\text {iii }}$ the other games are English mediated. All of these games are overwhelmingly played by boys, with $90 \%$ of 13-16 year-old boys playing digital games compared to only 36\% of girls in the same age group (for whom The Sims ${ }^{i v}$ was the most popular game). For the boys $44 \%$ of 13-16 yearolds report playing digital games for more than three hours every day.

In gaming trends change very quickly. While, for example, World of Warcraft was the second most popular digital game in 2010, it is joint fifth in popularity in 2012/2013 (Swedish Media Council, 2010, 2013). A noticeable trend in 2013 and 2014 has been the increased popularity of League of Legends, as well as two other 'action real time strategy' games, Defence of Ancients 2 (DOTA2) and Heroes of Newerth (HON). ${ }^{\mathrm{v}}$ Many of the English-mediated games commonly played by 13-16 year-olds in Sweden - especially World of Warcraft, League of Legends, Defence of Ancients 2 and Heroes of Newerth - put players in environments that place very high demands on understanding and communication. As revealed in recent research (e.g. Liang, 2012; Peterson, 2010, 2012; Reinders \& Wattana 2011; Thorne, 2008), playing multiplayer action and role-playing games can have a positive impact on language 
acquisition. Not only do such games provide rich lexical environments, the design features of 'massively multiplayer online role-playing' and 'action real time strategy' games also play an important role in developing communicative skills. As for example Peterson (2010) explains, network-based text and voice chat provide multiple communication channels for real-time interaction and feedback, challenging themes engage players in the pursuit of complex quests, while goal-based interaction encourages the development of collaborative social relationships. Further, the use of personal avatars can enhance a player’s in-game immersion, reduce inhibition and facilitate risk-taking.

Mapping the amount of time students in Sweden spend in English-mediated environments, Sundqvist (2009), and Olsson (2011), asked samples of $9^{\text {th }}$ grade (15-year-old) students to maintain language diaries over designated periods of time. In these diaries students recorded the amount of time they spent each day on English-mediated activities, such as watching TV, watching films, visiting Internet sites, playing digital games and listening to music. While in her study Sundqvist found that students $(n=80)$ spent an average of over 18 hours a week in English-mediated environments (20.8 hours per week for boys, and 16.4 hours per week for girls), in Olsson's study the average time that students $(n=74)$ were in contact with English was just over 20 hours per week (23 hours per week for boys, and 17.5 hours per week for girls). vi

In Sundqvist's (2009) study (also reported on in Sundqvist and Sylvén (2012)), the impact of out-of-school encounters with English on tests of students' oral proficiency and vocabulary skills was also investigated. In both cases positive correlations were found between the amount of time spent in English-mediated environments and students' test scores. Findings also revealed that some out-of-school activities had a greater influence on test results than others. Activities that involved a greater degree of interaction - for example digital gaming and visiting English-mediated Internet sites - were found to have more of an impact than receptive activities such as listening to music and watching films and TV. A gender effect was also found. Not only did boys spend more time than girls on interactive activities (particularly digital gaming), but for them the impact of out-of-school English-mediated activities on vocabulary and oral skills was also greater. In Olsson's (2011) study, which focused on written proficiency, similarly significant correlations were found. Here too students who were frequent users of English outside the classroom - again more boys than girls - performed better on tests of writing proficiency. 


\section{Learning English in School}

Having sketched a picture of young people's encounters with English outside school, I turn now to consider the situation inside the classroom. Alongside mathematics and Swedish, English is a core subject, which most students start learning in the first grade (age 7). Although schools have discretion in allocating time to English across different stages of secondary education, by grade 6 (age 12), the average secondary school student will usually have two 50- to 60-minute lessons per week.

During the period October 2010 to February 2011, an extensive subject evaluation of English in grades 6 through to 9 was conducted by the Swedish Schools Inspectorate (2011). Structured observations of nearly 300 lessons at 22 different schools from different parts of the country were carried out. Interviews with randomly selected students and teachers of English at these schools were conducted, and questionnaires were completed by some 3000 students. In reporting on the quality of English education, a number of problems were identified.

In the majority of the classrooms visited, the inspectors describe learning environments that were secure and supportive. However the inspectors also found little evidence of activities that awakened students' interest, or provided them with any real challenge (see also Busse, this volume). Many of the lessons observed were constructed around commercially-produced learning materials, with a 'one-size-fits-all' approach being common. Instances where teachers used authentic materials were few. The tasks and questions students were given often anticipated 'right or wrong' answers, and while students would frequently be provided with texts about other countries and other cultures, rarely were they required to do more than answer questions and translate these texts into Swedish. Activities designed to accommodate students' differing interests were rarely encountered. Furthermore, in nearly half of the lessons observed, few opportunities for oral interaction were provided. Indeed, in only one fifth of all classes was English spoken consistently throughout the lesson. Worryingly, in some lessons hardly a word of English was spoken. The use of digital technologies was also extremely rare, a finding confirmed in the student questionnaire where $80 \%$ of students reported that computers were infrequently or never used in English lessons. 
In many of the interviews, students talked about how the working methods used in English classes could be mundane, and learning not particularly challenging. In an otherwise demanding school day, students spoke about how English could provide a welcome opportunity to relax; the format of lessons were predictable and the demands not too high. Furthermore, a difference between English in school and English outside, particularly in the type of communication that takes place, was also identified. In particular students talked about how there were few, if any, opportunities to make use of out-of-school experiences of English in the classroom, and how they are much more comfortable using English outside school than inside.

\section{A situation unique to Sweden?}

Although the combination of a high level of technological development and the small linguistic community might suggest that the in-school/out-of-school differences in students' encounters with English found in Sweden may differ from those of students in other countries, it is interesting that similar phenomena have recently been reported in other settings. Referring to anecdotal evidence from teachers from a number of different European countries, Ushioda (2013) describes how many paint a similar picture; students seem to find English in school boring and invest little effort in classroom activities. Because students may feel a greater sense of self-confidence and self-fulfilment when communicating in English in out-ofschool environments, this can mean that there are few incentives for them to work on the development of formal skills (Ushioda, 2013). Looking at the situation in Romania, Taylor (2013), for example, identifies a widespread feeling among students that, in school, they are not valued as individuals and their interests are not taken into account.

Recognising fundamental differences in students' in and out-of-school experiences of English, and the negative impact that such dissonances can have on motivation, Ushioda (2013) argues that teachers working in settings where English is part of the social fabric of young people's daily lives are now facing very real challenges in providing learning opportunities that can generate and sustain interest and motivation. As a means of addressing this challenge she emphasizes the importance of giving students possibilities to engage in personally meaningful activities where they can express their identities. As Ushioda (2011a) explains, when proper account is not taken of students' different social identities, motivation is likely to suffer. Teachers, she contends, need therefore to “invoke and orient to students' transportable identities in the classroom” and engage with their students “as 'people’ rather than as simply 
'language learners'”. This means giving them opportunities to build their own personally relevant connections between what they do in and outside of class, and allowing them "to speak as themselves" and to "engage and express their own preferred meanings, interests and identities through the medium of the target language” (Ushioda, 2011a: 17).

In a similar take on the problem, Henry (2013) has suggested that students' reluctance to engage in classroom learning can be understood in the sense that classroom activities lack authenticity. While many of the things students do in their leisure time that are Englishmediated, such as digital gaming, can often provide them with meaningful, positive and identity-confirming experiences, work done in school is frequently perceived as artificial and distant from 'reality'. Because, he explains, students are likely to compare the Englishmediated, identity-congruent activities they engage in outside school with the mundane and sometimes meaningless activities taking place in the classroom, their reluctance to invest in classroom work can be understood in terms of experiencing a lack of self-authenticity or feelings of "frustrated authenticity". Specifically, he contends, they lack "the scope to use the language in the same meaningful and self-relevant ways" that it is used in out-of-school environments, such as in digital gaming (Henry, 2013: 146).

As both Ushioda (2011a, 2011b, 2013) and Henry (2013) suggest, it is of great importance that pedagogical practices which bridge between the worlds in and outside the classroom, and which engage students' identities, are developed. However, even if context-bridging, identityconfirming pedagogies can be developed and implemented in instruction, such initiatives may not, on their own, be sufficient to engage students' interest and generate motivation. Beliefs about the ease and efficacy of different acquisition processes are also likely to have a fundamental impact on the ways learning is approached (Mercer et al., 2012). Thus, if students believe that English is most effectively learnt in naturalistic out-of-school situations, they may still be reluctant to put effort into classroom activities. It is therefore important that, in the context of the in-school/out-of-school dissonance, researchers and teachers develop an understanding of students' beliefs, the effects these can have on approaches to classroom work, and ways in which they can be addressed.

Taking data from the Swedish Schools Inspectorate's (2011) student questionnaire, in the sections that follow, I examine students' beliefs about the relative value of learning English in and out of school. Drawing on different theories of self-regulation, I consider how these 
beliefs can impact on classroom motivation, particularly for those students - mainly boys who believe that they learn most or nearly all of their English outside school. In attempting to generate insights into the ways in which beliefs about the relative efficacy of different acquisition contexts might impact on approaches to classroom learning, my intention is not to make any general claims, nor draw any specific conclusions. Rather, I want to explore some of the possible consequences that students' beliefs may have for classroom motivation and to identify areas that could usefully be explored in future research.

\section{Beliefs about the effects of out-of-school encounters with English}

As we have seen, students in Sweden spend substantial periods of time in English-mediated environments that are often personally meaningful, identity-confirming and in which they feel comfortable using the language. Contrasted with the rather negative experiences many have of learning English in the classroom, it is perhaps not surprising that large numbers of students believe that much of their language competence is gained in out-of-school settings. In the Swedish Schools Inspectorate's student questionnaire, one of the items asked participants $(n=2,868)$ to indicate where they believed that they had learnt most of their English. Of the responses received, substantially more than half believed that they had learned more, or at least as much of their English, outside of school. Furthermore, 16\% of all students said they believed that they had learnt most or nearly all of their English outside of school (see Table 1). 
Table 1. Responses to the question: 'Where do you believe you learned most of what you know in English?'

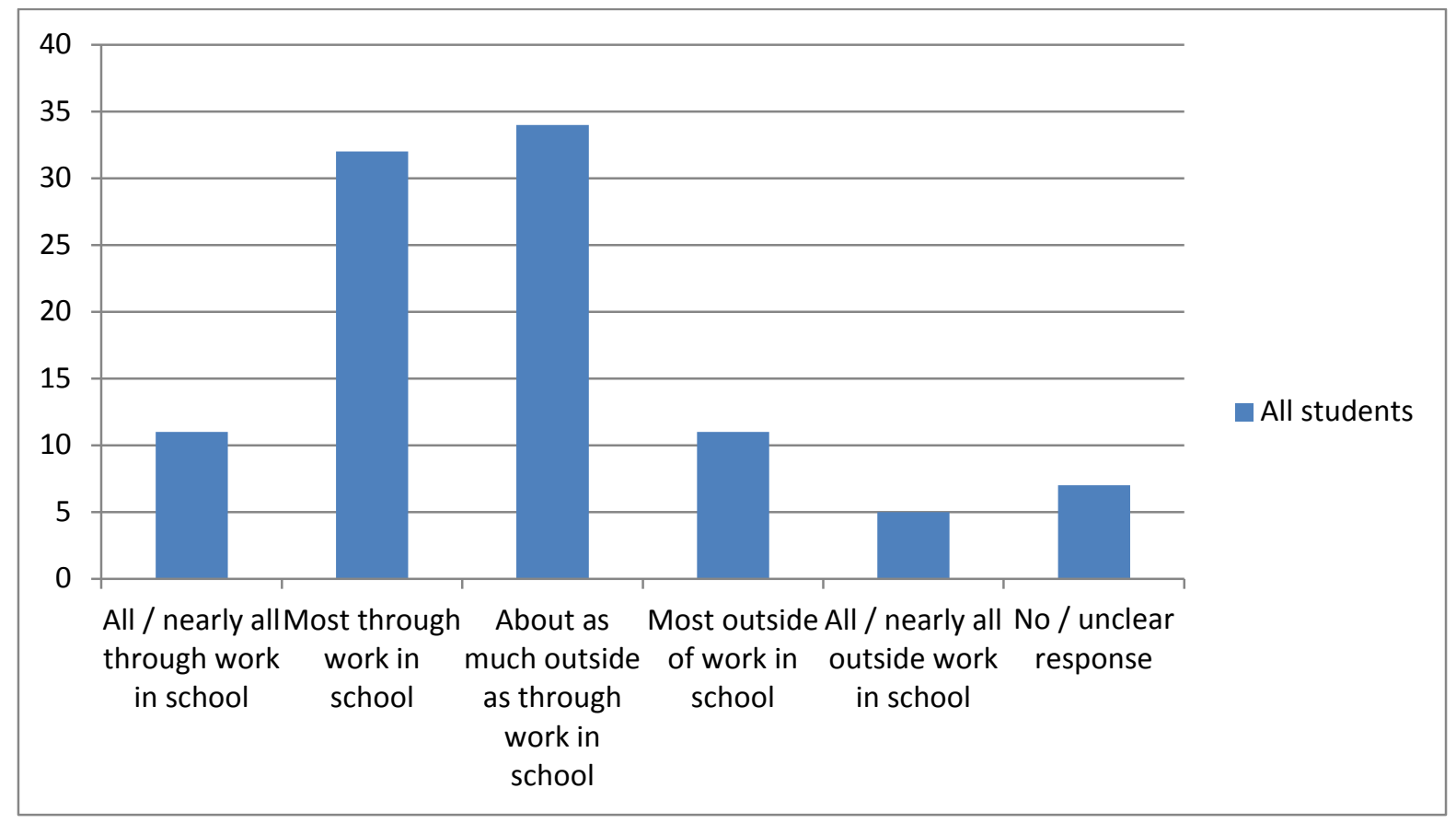

\section{Learner beliefs}

Because they have been investigated in diverse fields, and because researchers have different agendas, learner beliefs are, conceptually, difficult to pin down. Unlike knowledge - which is based on objective 'fact' - beliefs are based on evaluation and judgment. This means that the researcher has to make inferences about underlying states. Beliefs are thus "inferred from what people say, intend, and do” (Pajares, 1992: 314). With regard to beliefs about second language acquisition, Barcelos (2003: 8) emphasises the importance of the cultural setting and social milieu, making the point that understanding students' beliefs “means understanding their world and their identity”. Furthermore, because beliefs about SLA are variable, contextembedded and complexly interrelated, they encompass not just matters that people perceive to be true, and are sufficiently confident about to act upon, but also knowledge which is contingently accepted as true (Barcelos, 2003).

\section{Self-regulation}

As Bandura $(1977,1986)$ has demonstrated, the beliefs people hold about their abilities and the consequences of their efforts impact not only on the ways they behave, but also on the cognitive and affective processes involved in the pursuance of different goals. Self-regulation describes the ways in which individuals activate and sustain the cognitions, affects and 
behaviours that are systematically oriented to learning goals (Schunk \& Zimmerman, 2008; Zimmerman, 2000). Self-regulation functions thus as an overarching construct, encompassing a wide range of differing activities that, for example, include organizing and coding information to be learned, attending to and concentrating on instructions, and establishing positive conditions for learning. It also encompasses broader-based beliefs about learning, such as holding positive beliefs about the capacity to learn, beliefs about the anticipated outcomes of learning, and beliefs about the value of learning (Pintrich, 2000). From the range of different theories relating to self-regulation, three seem to offer particularly interesting lenses through which to consider the motivational consequences of out-of-school encounters with English; Bandura's $(1977,1986)$ theory of self-efficacy (in SLA contexts applied by Mills et al. (2007)), Weiner's (1992) attribution theory (used in SLA by Hsieh (2012)), and Dweck's, (1999) theory of implicit theories of intelligence (recently applied in SLA contexts by Mercer and Ryan (2010)).

\section{Self-efficacy beliefs}

As Bandura (1986) has explained, through processes of self-evaluation, where the individual reflects upon and evaluates thoughts, feelings and experiences, people are able to condition the ways in which they think and behave. Through such processes people make judgments about their capabilities to accomplish different tasks and about the activities in which they wish to engage. Rooted in core beliefs about individual agency - the power to bring about change as a result of one's actions - self-efficacy forms the foundation for motivation. This, as Pajares (2008) explains, is because unless people believe that their actions can produce desired outcomes, they will not have the incentive to pursue particular behaviours, or to persevere when difficulties are encountered.

Expectations about future behaviours are rooted in experiences of the consequences of previous actions. Based on self-evaluation of prior experiences, choices are made about the efficacy of future courses of action. Importantly, beliefs about self-efficacy relate not to actual ability, but rather to what, given her/his own particular set of skills, the individual believes she/he can accomplish (Pajares, 2008). For this reason, self-efficacy beliefs have a greater impact on the effort expended on an activity than prior successes, skills or knowledge (Bandura, 1997). Individuals who hold beliefs about their self-efficacy are more focused in their learning behaviours and, as Pajares and his colleagues (Mills et al., 2007; Pajares, 2008; Pajares et al., 2000) make clear, these beliefs can be very powerful, enabling the individual to 
continue with a course of action even in the face of obstacles and adversity. Moreover, when failures are experienced, individuals who believe in their own self-efficacy are more likely to attribute them to deficiencies in effort or knowledge, with setbacks less likely to impact on future effort than would be the case for less self-efficacious individuals.

Investigating self-efficacy in the context of foreign language learning in a sample of US university students studying French, Pajares and his colleagues (Mills et al., 2007) found it to be a predictor of achievement. One construct in particular, self-efficacy for self-regulation that is to say the perceived ability to use appropriate strategies to plan, monitor, and complete a task - was found to have a particularly strong effect. Additionally, self-efficacy for selfregulation was also found to be positively correlated with perceptions of the value of French and French culture, leading the authors to conclude that, in the classroom context, levels of self-regulation will be related to students' interest in the language and cultures associated with it. In another study examining self-efficacy and achievement in language learning, this time in a Korean context with $9^{\text {th }}$ grade students learning English, Hsieh and Kang (2010) found, as anticipated, the two variables to be positively correlated.

In what sense then, in the context of Swedish students' encounters with English, might a selfefficacy perspective contribute to understanding how out-of-school experiences can impact on classroom motivation? Even if it were empirically possible to quantify the amount of English students actually acquire in leisure time activities, the important point to bear in mind is not whether beliefs about learning English outside school in fact correspond with actual acquisition, but, rather, the strength and impact that such beliefs have on learning behaviours. If students firmly believe that one of the two domains in which English is encountered - the 20 or so hours a week they spend in English-mediated environments (as opposed to the couple of hours in the classroom) - is the primary reason for increases in skills and ability, this is likely to have a negative impact on levels of self-regulated behaviour in the classroom. If students do not believe that their actions produce desired outcomes - i.e. that efforts expended in the classroom do not lead to a fluent command of English - then there will be little incentive for them to actively engage in the learning activities on offer, or to direct effort to areas of perceived difficulty, such as grammar. It is therefore important that, in settings where young people regularly encounter English in out-of-school contexts, research with a focus on students' self-efficacy beliefs in relation to the perceived value of different learning contexts is carried out. 


\section{Attributions}

Attributions are beliefs about the causes of outcomes. Like self-efficacy, attributions have an important impact on self-regulation. Building on Heider's (1958) suggestions that people attribute outcomes to internal factors, such as ability and motivation, as well as to external factors in the surrounding environment, Kelley (1967) argues that, faced with a range of competing possibilities, people are selective in the attributions they make, settling on explanations that best seem to fit the event. Thus, in accounting for their successes and failures, students will attribute them to factors such as ability, effort, task difficulty and luck (Weiner, 1992; Weiner et al. 1971).

Developing an understanding of students' attributions is particularly important because, like self-efficacy beliefs, they are likely to impact on decisions about where to channel effort and resources. Similarly, the accuracy of attributions is not itself important; even dubious causal attributions that fail to reflect objectively observable reasons for success or failure are sufficient to generate self-regulated learning behaviours (Weiner, 2000). Further, people tend also to identify single causal factors when, in reality, reasons might be multiple. With a focus on L2 acquisition, Hsieh (2012) (see also Hsieh \& Schallert, 2008) offers the following explanation of how attributions can impact on learning behaviour:

If a student believes that his or her success in learning a foreign language is due to the amount of effort he or she has put into learning (e.g., practicing speaking with a native speaker), the student will expect to do well the next time he or she approaches similar tasks assuming that effort can determine the outcome. Or, if the student fails in a language class and believes that failure is due to his or her low ability (i.e., the person believes they do not have a 'gift' for learning a foreign languages), the student may avoid similar tasks in the future so as to avoid failing again. (Hsieh, 2012: 91)

In the context of the two different learning environments identified by the students in the Swedish Schools Inspectorate's survey, locus, that is to say whether the attribution is internal or external to the individual, is likely to have a particular bearing on the attributions students make. As Schunk (2008) explains, locus impacts on learners' affects and emotions in the sense that greater achievement satisfaction is generated when development is attributed to internal, as opposed to external causes. Because of the reciprocal relationship between affect 
and attributions - we are more likely to make attributions that make us feel good - there may be a tendency among the students surveyed to attribute successes to the natural acquisition of skills as a result of spending time in English-mediated environments (an internal locus), as opposed to the effects of classroom-based learning and focused instruction (an external locus). Thus there may exist a dissonance between the actual effects on proficiency of out-ofschool encounters with English, and what students attribute to such experiences. As with selfefficacy beliefs, research is needed on the nature and effects of the attributions students make in relation to the English language skills they develop, with studies focusing on affective factors being particularly important.

\section{Self-theories of intelligence}

As Dweck and her associates (Dweck, 1999; Dweck \& Leggett, 1988) have demonstrated, the views that students hold about intelligence impact on their willingness to engage in, selfregulate and generate motivation for different learning activities. Most individuals hold one of two general views about intelligence. Some, so-called 'entity theorists', believe that intelligence is a deep-seated commodity, more or less innate in nature, and which changes little, if at all, over time. Others, 'incremental theorists', believe that intelligence is malleable and can develop over time as a result of focused learning and effort (Dweck, 1999; Dweck \& Master, 2008). For students who subscribe to an entity view of intelligence, appearing smart is more important than learning, while students who hold incremental views are focused on learning new things, even when there is a risk of losing face. For the former group, success involves being smarter than others, while for the latter, the development of knowledge and skills is the primary aim. When it comes to the effort invested in study, clear differences have been found between the two types of learners. For entity theorists, natural ability is regarded as the key to success and effort is equated with low intelligence. Incremental theorists however see effort in a different way. For them, hard work leads to learning and generates intelligence. If failure occurs, it is put down to insufficient effort and not, like entity theorists, low intelligence. Because entity theorists believe that if you are good at something, hard work should not be necessary, and that if you do have to work hard at something you are probably not very good at it, the central goal in education is to exert the minimum amount of effort (Blackwell et al., 2007; Dweck \& Master, 2008).

In making the case for SLA applications of implicit theories of intelligence (or 'mindsets' as they are also referred to) Mercer and Ryan (Mercer \& Ryan, 2010; Ryan \& Mercer, 2011, 
2012) identify two different types of what they call 'language learning mindsets'. A fixed language learning mindset, they explain, describes a person who holds the belief that successful language learning is attributable to natural talent or to an innate ability. Someone, on the other hand, who holds the belief that language skills can be developed as a result of effort and practice is said to have a growth language learning mindset. In developing these ideas, Mercer and Ryan argue that strong beliefs about the efficacy of acquisition in the naturalistic setting of a study abroad context - often entirely separate from classroom learning in the students' home countries - can have negative consequences in terms of demotivating and disempowering learners in the classroom. In pointing to the negative effects of EFL study abroad experiences, particularly for students with fixed language learning mindsets, Ryan and Mercer make the point that, in the Japanese and Austrian contexts in which their studies have been carried out, countries where English is spoken remain "a constant background presence in foreign language learning” (Ryan \& Mercer, 2011: 166). For such learners, they argue, time spent abroad may negate the need for effortful learning at home and compensate for any perceived deficiencies in talent. In extreme cases, learners may take the view that the language development that takes place in naturalistic settings can never be achieved through classroom learning (Ryan \& Mercer, 2011).

If, as these findings seem to suggest, periods of study abroad can diminish the learner's sense of individual agency, trigger demotivation and impact negatively on approaches to classroom learning, what then of a situation where, as in Sweden, it is not just TL (Target Language) countries or TL cultures that form a "constant background presence”, but all the TL-mediated activities engaged in as soon as the school day ends, on weekends and during school holidays? In that English is an indissociable part of the social fabric in Sweden, ever-present in some of the most important social/cultural practices where young people's identity work takes place (for a discussion see Henry \& Goddard, in review), this might mean that (i) more learners of English are likely to possess a 'fixed language learning mindset' than those in other countries, and (ii) that the strength of the beliefs undergirding such mindsets may be stronger and more resistant to mindset-changing interventions (Ryan \& Mercer, 2012) than elsewhere.

Mercer and Ryan's language learning mindset theory offers a particularly interesting angle of interpretation when considering the effects of students' beliefs about the relative value of the different contexts in which English is learnt. Given that the range of responses to the 
questionnaire item on students' beliefs about the efficacy of different learning contexts would seem to indicate that existence of both 'fixed' and 'growth' second language learning mindsets, the use of either longitudinal or retrodictive designs (retrodiction being a strategy by which the usual research direction is reversed, where the researcher starts at the end with the outcomes and then traces things back to see why these outcomes came about (see e.g. Chan et al., 2014; Dörnyei, 2014)), could shed light on the developmental trajectories leading to these different mindset types.

\section{Gender differences in beliefs about learning English}

In the questionnaire data $(n=2,868)$ it is interesting to note that the responses of girls and boys differ in noticeable ways. As shown in Table 2 (below), substantially more girls (48\%) than boys (37\%) believed that they learnt most or all of their English in school. While the proportion believing that they learnt equally much English as a result of school work as they did outside school was roughly similar (girls 35\%, boys 33\%), striking differences can be seen in the categories 'learn most of my English outside school' (girls 8\%, boys 14\%) and 'learn all, or nearly all of my English outside school' (girls 3\%, boys 6\%). Given that in a recent study Henry and Cliffordson (2013) failed to find any gender-related differences in Swedish $9^{\text {th }}$ grade students' ideal English-speaking/using selves, the rather dramatic divergences in students' beliefs about learning English warrant further investigation. In the sections that follow the theories previously discussed are revisited, this time considering whether gender-related differences generally found in self-efficacy, attribution and self-theory research have the potential to shed light on differences in girls' and boys' beliefs about learning English.

Table Two. Responses to the question: 'Where do you believe you learned most of what you know in English?' 


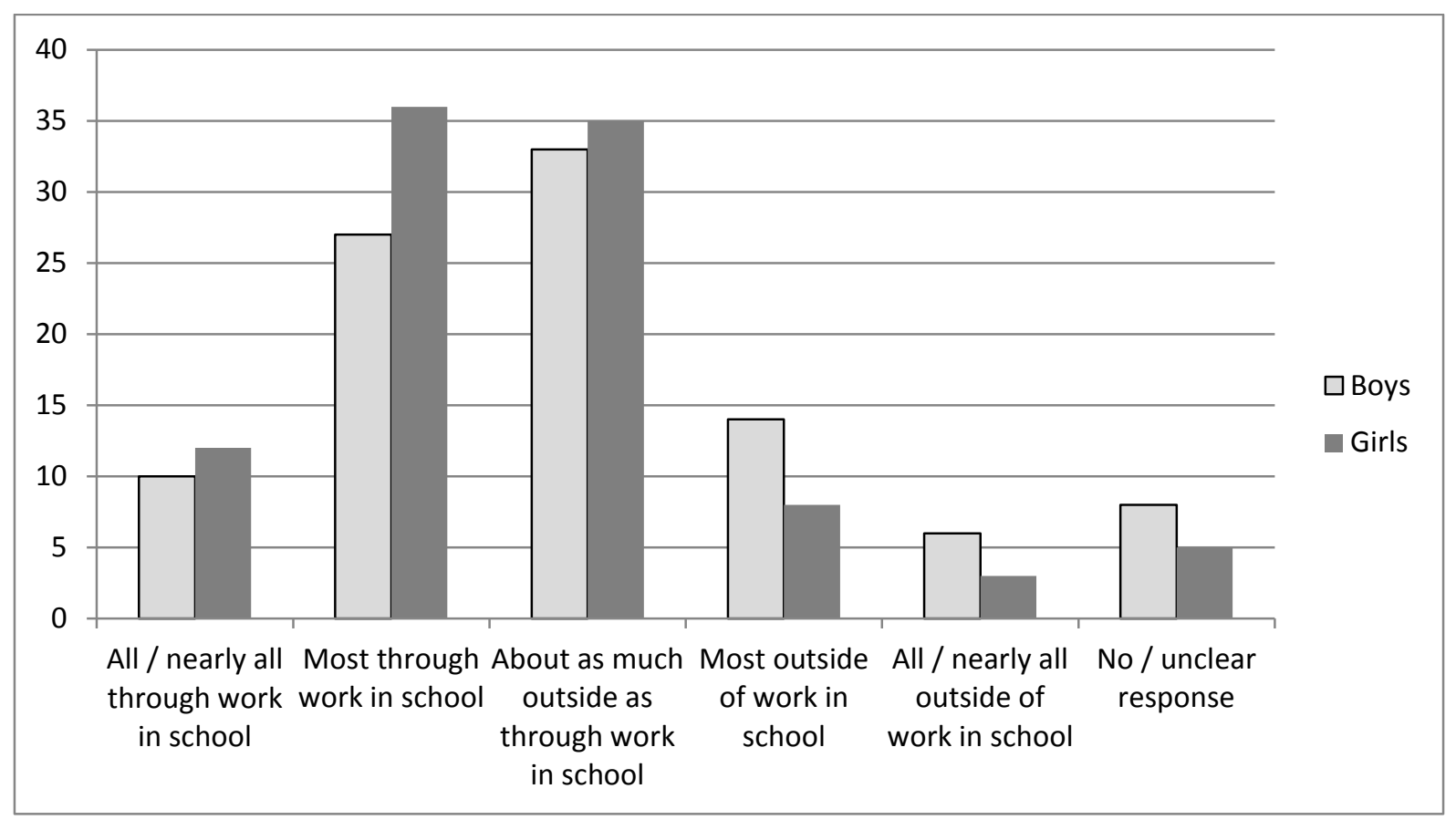

\section{Self-regulation and gender}

In common with other constructs in psychology where gender differences have been found, differences in females' and males' self-regulated learning tend to be domain related. Overall, studies indicate that girls make greater use of self-regulation strategies than boys, that they tend to be more self-disciplined, and that they exercise more conscious control over their learning (see e.g. Dweck, 1999). Indeed, as Meece and Painter (2008) report, data across a range of studies indicate that girls' cognitive investment in learning activities often reaches deeper levels than boys'. Consequently the differences in girls' and boys' beliefs about the relative efficacy of different sites for learning English, and the impact on motivation mediated by such beliefs, may stem from deep-rooted differences in levels of investment in classroom learning generally.

\section{Self-efficacy beliefs}

Self-efficacy beliefs form a field where a considerable amount of gender-related research has been carried out, and where domain-related differences often emerge. Numerous studies have shown how in mathematics, science and computing, boys tend to report stronger self-efficacy beliefs than girls. In arts subjects the reverse is often found, where girls self-efficacy beliefs can be stronger (Meece \& Painter, 2008). In their study of the self-efficacy and other motivational self-beliefs of college learners of French as a foreign language, Mills et al. (2007) found that, in addition to placing a higher value on French, having a greater interest in 
the language, and deriving greater enjoyment from learning French and about French culture, female students also had a stronger sense of self-efficacy. In considering factors that could explain this and similar findings (see e.g. Pajares \& Valiante, 2001), Pajares (2008: 124) suggests that one reason could be due to "differences in the beliefs that students hold about their gender rather than by their gender per se”. That is to say, gender differences might be a function of gender stereotypic beliefs, themselves rooted in differing educational expectations for girls and boys, where boys are expected to be good at mathematics and girls are expected to be good at languages (Pajares \& Valiante, 2001).

In terms of the contexts in which English is learnt, gender-related differences, as we have seen, are found not just in students' beliefs, but also the extent to which they participate in English-mediated activities and the type of activities they engage in. Largely the result of their interest in digital gaming, boys spend more time engaged in English-mediated activities (Sundqvist, 2009). However, in the context of students' self-efficacy beliefs, whether or not those who claim to learn more of their English outside of the classroom actually do develop most of their skills in this way, is not in itself important (see e.g. Nisbett \& Ross, 1980). Because the individual believes this to be true, even in the face of contradictory evidence such as the tangible results of school-based learning - this can impact on motivation, effort and focus (Bandura, 1997; Pajares, 2008). In this respect it is interesting to note that, in Sundqvist's (2009) study, where the amount of time $9^{\text {th }}$ grade students spent in Englishmediated environments outside of school was compared with measures of oral proficiency and vocabulary levels, although statistically significant positive correlations were found, the coefficients were relatively small ( $r_{s}=.31$ and $r_{s}=.35$ respectively), indicating that the effect of out-of-school activities on proficiency might not be that substantial.

Nevertheless, regardless of the accuracy of the belief, a reciprocal relation can arise; if proportionately more boys than girls believe that they learn more English outside school - for example by playing digital games - they may be less likely to exert themselves in the classroom. Reinforced by messages in popular discourse that boys become good at English through playing lots of digital games, these beliefs can provide the underpinning for an emerging stereotype of the young male who, safe in the knowledge he can effortlessly gain English from everyday digital activities, does not need to take classroom learning particularly seriously. Thus the gender gap in self-regulated learning strategies and motivated learning behaviour generally noticed in school may be further accentuated in settings such as Sweden 
where, in digital gaming, many boys spend substantial periods of time in environments they perceive as to be particularly conducive to language acquisition.

\section{Attributions}

As Meece and Painter (2008) explain, in studies of causal attribution gender differences have been found in varying educational domains. Generally, girls are less likely than boys to attribute their successes to natural talent (Eccles-Parsons et al., 1984; Meece \& Painter, 2008). However these results have been found to vary across domains. While in masculine sex-typed subjects, such as mathematics and science, girls are more likely to attribute success to effort and hard work, in arts and language subjects, gender differences have not been as apparent (Meece \& Painter, 2008).

The reasons underlying the gender differences in Swedish students' beliefs about the efficacy of different sites in which English is learnt are likely to be many in number and closely interrelated. One aspect of attributions though that may have a particular bearing on differences in students' beliefs is the locus dimension, that is to say whether girls' and boys' internal and external success attributions differ. Analogous to the idea that people who hold a belief that they lack a gift for foreign languages might feel that it is meaningless to put effort into learning (cf. Hsieh, 2012), a belief that English can best be acquired without effort in naturalistic contexts might result in similar approaches. In particular, if more so than girls, boys attribute successes in English to out-of-school learning - language skills being a naturally acquired by-product of engagement in personally meaningful activities such as digital gaming (an internal locus) - they may be less motivated to engage in classroom learning activities.

\section{Self-theories of intelligence}

While the effects of gender on self-efficacy beliefs and attributions have been widely studied (Meece, 2006; Meece \& Painter, 2008), relatively little research has focused on differences in females' and males' self-theories of intelligence. Of the work that has been carried out, in a sample of US $8^{\text {th }}$ grade students Leggett (1985) (cited in Dweck, 1999; see also Dweck \& Leggett, 1988) found striking gender differences, with girls being significantly more likely than boys to hold an entity theory of intelligence. Further, among all students holding entity theories, girls were found to be much more likely to choose tasks that provided safe options, thus avoiding the risk of mistakes and failure. Similar results have been obtained by Licht \& 
Shapiro (1982) (as cited in Dweck, 1999), who found that academically-gifted girls preferred tasks on which they felt they were likely to do well, and Chen and Pajares (2010) who found that, in relation to science, boys reported slightly higher incremental views of ability than girls. Consequently, Dweck (1999) suggests that not only do academically-gifted girls attribute failures to entity-causes - i.e. a lack of intelligence - but in many educational domains they have lower estimates of ability and lower expectations of success. This, she argues, stems from “a diet of early success and praise” (Dweck, 1999: 124), meaning that in subsequent stages of education, girls operate in a framework "in which challenge is a threat and errors are a condemnation” (Dweck, 1999: 55).

In adapting Dweck’s theories to language learning, Ryan and Mercer (2012), as we have seen, explain that a fixed language learning mindset describes the belief that success in language learning is attributable to innate ability, while a growth language learning mindset involves the belief that language learning abilities can be developed as a result of effort, practice and hard work. ${ }^{\text {vii }}$ Because implicit theories of intelligence are domain-specific and are likely to vary across cultures, findings of gender differences in one domain and from one particular culture may not translate to other domains or settings. Thus the entity theories of intelligence found generally to be held by girls in US junior high school (Dweck \& Leggett, 1988; Leggett, 1985; Licht \& Shapiro, 1982) may not have any direct bearing on the belief that successful language learning is attributable to the 'talent' of being able to acquire the language in natural settings (which, as we have seen, in a Swedish context may be more strongly held by boys). Because mindsets offer a potentially rewarding lens through which to examine classroom motivation in settings where English constitutes "a constant background presence” (Ryan \& Mercer, 2011: 166), research focusing on the role played by gender in the development of language learning mindsets would be of particular value.

\section{Conclusions}

In this chapter I have described how, in its recent evaluation of the quality of learning environments in English classrooms, the Swedish Schools Inspectorate (2011) found that little account was taken of students' out-of-school encounters with English. A picture is painted of classrooms where teachers fail to integrate students' interests into the activities on offer and where students do not feel particularly challenged, tending to regard English lessons as providing a welcome opportunity for rest and relaxation. I have also described how young people in Sweden spend substantial amounts of time in English language environments, often 
engaged in personally-meaningful activities, such as digital gaming. Examining students' responses to a questionnaire item on beliefs about the relative efficacy of in and out-of-school learning environments, I have shown how many students hold the belief that they learn as much if not more English outside the classroom, with substantially more boys than girls believing that they learn most or nearly all of their English outside school. Examining these results through a self-regulation lens, I have suggested that theories about the effects of selfefficacy beliefs, attributions and self-theories of intelligence on learning and motivation can all provide useful perspectives from which to understand the phenomenon of students lacking the enthusiasm to engage with English in school currently witnessed in Sweden and, it would seem (Ushioda, 2013), is also emerging elsewhere in Europe.

Even if the situation I have sketched out may be dissimilar to that in other social/educational contexts (for example in parts of Asia), given that English is continuing to entrench its position as a global lingua franca (Canagarajah, 2007; Graddol, 2006) and that, across the globe, young people are enjoying ever greater access to digital medias (many Englishmediated) the situation currently seen in Sweden could well develop in other parts of the world. To avoid the consequences of a situation where, because they believe English is best acquired in the naturalistic environments of out-of-school encounters, students fail to benefit from instruction in the formal elements of language and risk losing out on skills important for higher education and future professional communication, it is important that both students and teachers are made aware of the consequences such beliefs can have on motivation and learning.

However, before work can be carried out investigating ways in which, in pedagogical interventions, awareness can be raised, beliefs modified and learning behaviours altered, the nature, origin and effects on motivation of students' language learning beliefs need to be properly investigated. Thus, in addition to qualitative studies into beliefs about learning in natural and instructed contexts held by different types of students, in different social/cultural/educational contexts, and for different languages (see e.g. Busse, this volume, for a study on German as an FL), studies that consider the impact of learning beliefs on students' classroom motivation are also needed. Given that gender roles and gender stereotyping might be highly implicated in the formation of beliefs about learning English, particular focus should be directed to the ways in which female and male learners might 
differently view the relative efficacy of in and out-of-school contexts and the ways in which these beliefs may have an impact on motivation.

\section{References}

Airey, J. (2009). Science, language and literacy: Case studies of learning in Swedish university physics. Uppsala: Uppsala Dissertations from the Faculty of Science and Technology.

Bandura, A. (1977). Self-efficacy: toward a unifying theory of behavioural change. Psychological Review, 84, 191-215.

Bandura, A. (1986). Social foundations of thought and action: A social cognitive theory. Englewood Cliffs: Prentice Hall.

Bandura, A. (1997). Self-efficacy: The exercise of control. New York: Freeman.

Barcelos, A. M. F. (2003). Researching beliefs about SLA: A critical review. In P. Kalaja \& A. M. F. Barcelos (Eds.). Beliefs about SLA: New research approaches (pp. 7-33). New York: Springer.

Blackwell, L. S., Trzesniewski, K., \& Dweck, C. S. (2007). Implicit theories of intelligence predict achievement across an adolescent transition: A longitudinal study and an intervention. Child Development, 78, 246-679.

Canagarajah, A. S. (2007). The ecology of global English. International Multilingual Research Journal 1 (2), 89-100.

Chan, L., Dörnyei, Z. \& Henry, A. (2014). Learner archetypes and signature dynamics in the language classroom: A retrodictive qualitative modelling approach to studying L2 motivation. In Z. Dörnyei, P. D. MacIntyre \& A. Henry (Eds.). Motivational dynamics in language learning. Bristol: Multilingual Matters.

Chen, J. A., \& Pajares, F. (2010). Implicit theories of ability of grade 6 science students: Relation to epistemological beliefs and academic motivation and achievement in science. Contemporary Educational Psychology, 35, 75-87.

Dörnyei, Z. (2014). Researching complex dynamic systems: 'Retrodictive qualitative modelling' in the language classroom. Language Teaching 47 (1), 80-91.

Dweck, C. S. (1999). Self-theories: Their role in motivation, personality and development. Hove: Psychology Press.

Dweck, C. S., \& Leggett, E. L. (1988). A social-cognitive approach to motivation and personality. Psychological Review, 95, 256-273.

Dweck, C. S., \& Master, A. (2008). Self-theories motivate self-regulated learning. In D. H. Schunk \& B. J. Zimmerman (Eds.). Motivation and self-regulated learning: Theory, research and applications. (pp. 31-51). New York: Lawrence Erlbaum Associates.

Eccles-Parsons, J., Adler, T. F., \& Meece, J. L. (1984). Sex differences in achievement: A test of alternative theories. Journal of Personality and Social Psychology, 46, 26-43.

European Commission (2012). SurveyLang: The European Survey on Language Competencies. Brussels: European Commission.

Forbes Magazine (2014). http://www.forbes.com/sites/insertcoin/2014/01/27/riots-league-oflegends-reveals-astonishing-27-million-daily-players-67-million-monthly/. Accessed 28 January, 2014. 
Graddol, D. (2006). English next: Why global English may mean the end of 'English as a foreign language'. London: British Council.

Henry, A. (2013). Digital games and ELT: Bridging the authenticity gap. In E. Ushioda (Ed.). International perspectives on motivation: Language learning and professional challenges. (pp. 133-155). Houndmills: Palgrave MacMillan.

Henry, A., \& Cliffordson, C. (2013). Motivation, gender and possible selves. Language Learning, 63 (2), 271-295.

Henry, A., \& Goddard, A. (in review). Being international: The second language identities of students on an English-medium university program in Sweden. Journal of Language and Identity in Education.

Heider, F. (1958). The psychology of interpersonal relations. New York: Wiley.

Hsieh, P. H. (2012). Attribution: Looking back and ahead at the 'why' theory. In S. Mercer, S. Ryan \& M. Williams (Eds.). Psychology for language learning (pp.90-102). Clevedon: Multilingual Matters.

Hsieh, P. H., \& Kang, H. S. (2010). Attribution and self-efficacy and their interrelationship in the Korean EFL context. Language Learning 60, 606-627.

Hsieh, P. H., \& Schallert, D. L. (2008). Implications from self-efficacy and attribution theories for an understanding of undergraduates' motivation in a foreign language course. Contemporary Educational Psychology, 33, 513-532.

Kelley, H. H. (1967). Attribution theory in social psychology. In D. Levine (Ed.). Nebraska Symposium on Motivation (Vol. 15, pp. 192-238). Lincoln: University of Nebraska Press.

Leggett, E. L. (1985). ‘Children’s Entity and Incremental Theories of Intelligence: Relationship to Achievement Behaviour', paper presented at the annual meeting of the Eastern Psychological Association, March, Boston.

Liang, M.Y. (2012). Foreign ludicity in online role-playing games. Computer Assisted Language Learning, 25 (5) 455-473.

Licht, B. G., \& Shapiro, S. H. (1982). Sex differences in attributions among high achievers. Paper presented at the meeting of the American Psychological Association, Washington DC.

Meece, J. L. (2006). Introduction to special issue. Explaining women's math and science related career choices at the end of the20th century: Large scale and longitudinal studies from four nations. In H. M. G. Watt \& J. S. Eccles (Eds.). Educational Research and Evaluation, 12, 297-304.

Meece, J. L., \& Painter, J. (2008). Gender, self-regulation, and motivation. In D. H. Schunk \& B. J. Zimmerman (Eds.). Motivation and self-regulated learning: Theory, research and applications (pp. 339-368). New York: Lawrence Erlbaum Associates.

Mercer, S., \& Ryan, S. (2010). A mindset for EFL: Learners' beliefs about the role of natural talent. ELT Journal, 64, 436-444.

Mercer, S., Ryan, S. \& Williams, M. (2012). Introduction. In S. Mercer, S. Ryan \& M. Williams (Eds.). Psychology for language learning (pp.1-9). Clevedon: Multilingual Matters.

Mills, N., Pajares, F., \& Herron, C. (2007). Self-efficacy of college intermediate French students: Relation to achievement and motivation. Language Learning, 57, 417-422.

Nisbett, R., \& Ross, L. (1980). Human inference: Strategies and shortcomings of social judgment. Engelwood Cliffs, NJ: Prentice Hall. 
Olsson, E. (2011). 'Everything I read on the Internet is in English': On the impact of extramural English on Swedish 16-year-old pupils' writing proficiency. Licenciate thesis, Faculty of Humanities, University of Gothenburg, Sweden.

Pajares, F. (1992). Teachers' beliefs and educational research: Cleaning up a messy construct. Review of Educational Research, 62, 307-332.

Pajares, F. (2008). Motivational role of self-efficacy beliefs in self-regulated learning. In D. H. Schunk \& B. J. Zimmerman (Eds.). Motivation and self-regulated learning: Theory, research and applications. (pp. 111-140). New York: Lawrence Erlbaum Associates.

Pajares, F., \& Valiante, G. (2001). Gender differences in writing motivation and achievement of middle school students: a function of gender orientation? Contemporary Educational Psychology, 26, 366-381.

Pajares, F., Britner, S. L., \& Valiante, G. (2000). Relation between achievement goals and self-beliefs of middle school students in writing and science. Contemporary Educational Psychology, 25, 406-422.

Peterson, M. (2010). Massively multiplayer online role-playing games as arenas for second language learning. Computer Assisted Language Learning, 23 (5) 429-439.

Peterson, M. (2012). Learner interaction in a massively multiplayer online role playing game (MMORPG): A sociocultural discourse analysis. ReCALL, 24(3), 361-380.

Pintrich, P. R. (2000). An achievement goal theory perspective on issues in motivation terminology, theory, and research. Contemporary Educational Psychology, 25, 92-104.

Reinders, H., \& Wattana, S. (2011). Learn English or die: The effects of digital games on interaction and willingness to communicate in a foreign language. Digital Culture and Education, 3(1), 4-28.

Ryan, S., \& Mercer, S. (2011). Natural talent, natural acquisition and abroad: Learner attributions of agency in language learning. In G. Murray, X. Gao, \& T. Lamb (Eds.). Identity, motivation and autonomy in language learning (pp. 160-176). Clevedon: Multilingual Matters.

Ryan, S., \& Mercer, S. (2012). Implicit theories: Language learning mindsets. In S. Mercer, S. Ryan \& M. Williams (Eds.). Psychology for language learning (pp.74-89). Clevedon: Multilingual Matters.

Schunk, D. (2008). Attributions as motivators of self-regulated learning. In D. H. Schunk \& B. J. Zimmerman (Eds.). Motivation and self-regulated learning: Theory, research and applications. (pp. 245-266). New York: Lawrence Erlbaum Associates.

Schunk, D. H., \& Zimmerman, B. J. (2008). Motivation and self-regulated learning: Theory, research and applications. New York: Lawrence Erlbaum Associates.

Sundqvist, P. (2009). Extramural English matters: Out-of-school English and its impact on Swedish ninth graders' oral proficiency and vocabulary. Karlstad, Sweden: Karlstad University Studies.

Sundqvist, P., \& Sylvén, L. K. (2012). World of VocCraft: Computer games and Swedish learners’ L2 English vocabulary. In H. Reinders (Ed.). Digital Games in Language Learning and Teaching (pp. 189-208). Basingstoke: Palgrave Macmillan.

Sylvén, L. K. (2013). CLIL in Sweden - why does it not work? A metaperspective on CLIL across contexts in Europe. International Journal of Bilingual Education and Bilingualism, 16 (3), 301-320.

Swedish Media Council (2010). Ungar och mediar 2010: Fakta om barns och ungas användning och upplevelser av medier (Young people and the media 2010: Facts on children and young people's media use and experiences). Stockholm: Statens Media Råd. 
Swedish Media Council (2013). Ungar och mediar 2012/2013: Fakta om barns och ungas användning och upplevelser av medier (Young people and the media 2012/2013: Facts on children and young people's media use and experiences). Stockholm: Statens Media Råd.

Swedish Schools Inspectorate (2011). Kvalitetsgranskning: Engelska i grundskolans årskurser 6-9. (Quality evaluation: English in secondary school grades 6 -9). Stockholm: Swedish Government.

Taylor, F. (2013). Listening to Romanian teenagers: Lessons in motivation and ELT methodology. In E. Ushioda (Ed.). International perspectives on motivation: Language learning and professional challenges. (pp. 35-60). Houndmills: Palgrave MacMillan.

Thorne, S. L. (2008). Transcultural communication in open Internet environments and massively multiplayer online games. In S. S. Magnan (Ed.). Mediating discourse online (pp. 305-330). Amsterdam: John Benjamins.

Ushioda, E. (2011a). Motivating learners to speak as themselves. In G. Murray, X. Gao, \& T. Lamb (Eds.). Identity, motivation and autonomy in language learning (pp. 11-24). Clevedon: Multilingual Matters.

Ushioda, E. (2011b). Language learning motivation, self and identity: Current theoretical perspectives. Computer Assisted Language Learning, 24(3), 199-210.

Ushioda, E. (2013). Motivation and ELT: Global issues and local concerns. In E. Ushioda (Ed.). International perspectives on motivation: Language learning and professional challenges. (pp. 1-18). Houndmills: Palgrave MacMillan.

Waters, J. K. (2007). On a quest for English. T. H. E. Journal, 34 (10), 26-32.

Weiner, B. (2000). Attributional thoughts about consumer behaviour. Journal of Consumer Research, 27 (3), 382-387.

Weiner, B. (1992). Human motivation: Metaphors, theories, and research. Newbury Park, CA: Sage.

Weiner, B., Frieze, I.H., Kukla, A., Reed, L., Rest, S., \& Rosenbaum, R. M. (1971). Perceiving the causes of success and failure. Morristown, NJ: General Learning Press.

World Economic Forum (2012). Global Information Technology Report. Geneva, Switzerland: WEF.

Zimmerman, B. J. (2000). Attainment of self-regulation: A social cognitive perspective. In M. Boekaerts, P. Pintrich, \& M. Zeidner (Eds.). Handbook of self-regulation (pp. 13-39). Orlando, FL: Academic Press.

\footnotetext{
i The C categories were not measured.

${ }^{\text {ii }}$ It is important to point out that contrary to the rigorous procedures of SurveyLang, EF's online survey does not meet generally accepted scientific standards in that participants are self-selected.

iii Anecdotal reports suggest that for FIFA in particular English language game settings are often selected.

iv The Sims can be played in both English and Swedish.

${ }^{\vee}$ For League of Legends this reflects a global trend where, according its manufacturer, Riot Games, as of January 2014, it was played worldwide by 27 million people daily, 67 million monthly and had recorded peaks of 7.5 million concurrent players (Forbes Magazine, 2014).

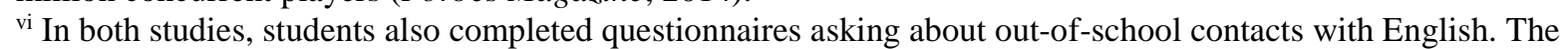
questionnaires revealed a substantially higher number of contacts with English. The language diaries are, however, regarded as more accurate measures.

vii In addition to the central role of natural talent, Ryan and Mercer (2011: 166) also incorporate an element which they identify as a unique feature of language learning mindsets, namely "beliefs about the importance or necessity of time spent in a country where the language is widely spoken and the relative 'naturalness' of the
} 
language learning process”. Therefore, when considering whether previous research on gender differences in implicit theories of intelligence (Dweck, 1999; Dweck \& Leggett, 1988; Leggett, 1985) can contribute in accounting for possible gender differences in language learning mindsets, it is important to bear in mind that these would only relate only to the conceptual core of the construct, that is to say beliefs about natural talent. 